\title{
Early Olfactory Involvement in Alzheimer's Disease
}

\author{
S. Christen-Zaech, R. Kraftsik, O. Pillevuit, M. Kiraly, R. Martins, K. Khalili and \\ J. Miklossy
}

\begin{abstract}
Background: In Alzheimer's disease (AD) the olfactory system, including the olfactory bulb, a limbic paleocortex is severely damaged. The occurrence of early olfactory deficits and the presence of senile plaques and neurofibrillary tangles in olfactory bulb were reported previously by a few authors. The goal of the present study was to analyze the occurrence of AD-type degenerative changes in the peripheral part of the olfactory system and to answer the question whether the frequency and severity of changes in the olfactory bulb and tract are associated with those of the cerebral cortex in AD. Material and methods: In 110 autopsy cases several cortical areas and the olfactory bulb and tract were analyzed using histo- and immunohistochemical techniques. Based on a semiquantitative analysis of cortical senile plaques, neurofibrillary tangles and curly fibers, the 110 cases were divided into four groups: 19 cases with severe (definite AD), 14 cases with moderate, 58 cases with discrete and 19 control cases without AD-type cortical changes. Results: The number of cases with olfactory involvement was very high, more than $84 \%$ in the three groups with cortical ADtype lesions. Degenerative olfactory changes were present in all 19 definite AD cases, and in two of the 19 controls. The statistical analysis showed a significant association between the peripheral olfactory and cortical degenerative changes with respect to their frequency and severity $(\mathrm{P}<0.001)$. Neurofibrillary tangles and neuropil threads appear in the olfactory system as early as in entorhinal cortex. Conclusion: The results indicate a close relationship between the olfactory and cortical degenerative changes and indicate that the involvement of the olfactory bulb and tract is one of the earliest events in the degenerative process of the central nervous system in AD.
\end{abstract}

RÉSUMÉ: Atteinte olfactive précoce dans la maladie d'Alzheimer. Contexte: Le système olfactif incluant le bulbe olfactif, qui fait partie du paléocortex limbique, est sévèrement atteint dans la maladie d'Alzheimer (MA). L'existence d'un déficit olfactif précoce et la présence de plaques séniles et d'amas neurofibrillaires dans le bulbe olfactif ont été rapportés par quelques auteurs. Le but de cette étude était d'analyser les changements dégénératifs de type MA en périphérie du système olfactif et de déterminer si la fréquence et la sévérité des changements dans le bulbe et le pédoncule olfactif sont associées à ceux observés dans le cortex cérébral dans la MA. Matériel et méthodes: Plusieurs zones corticales ainsi que le bulbe et le pédoncule olfactif ont été analysés au moyen de techniques d'histo et d'immunohistochimie chez 110 cas d'autopsie. Les 110 cas ont été divisés en quatre groupes, selon une analyse semi-quantitative des plaques séniles corticales, des amas neurofibrillaires et des fibres incurvées: 19 cas atteints de changements corticaux de type MA sévères (MA certaine), 14 cas de changements modérés, 58 cas de changements discrets et 19 témoins sans changements. Résultats: Le nombre de cas avec atteinte olfactive était très élevé, soit plus de $84 \%$ dans les trois groupes de cas ayant des lésions de type MA. Des changements olfactifs dégénératifs étaient présents chez les 19 cas de MA certaine et chez deux des 19 témoins. L'analyse statistique a montré une association significative entre les changements dégénératifs olfactifs et corticaux quant à leur fréquence et à leur sévérité $(\mathrm{P}<0,001)$. Les amas neurofibrillaires et de fibres tortueuses apparaissent dans le système olfactif aussi précocement que dans le cortex entorhinal. Conclusion: Ces résultats indiquent qu'il existe une relation étroite entre les changements dégénératifs olfactifs et corticaux et que l'atteinte du bulbe et du pédoncule olfactif est un des événements les plus précoces dans le processus dégénératif au niveau du système nerveux central dans la MA.

Can. J. Neurol. Sci. 2003; 30: 20-25

The olfactory system has extensive connections with the prepyriform cortex, amygdaloid nuclear complex and parahippocampal gyrus including entorhinal cortex, parts of the brain which are severely affected in Alzheimer's disease (AD). In $\mathrm{AD}$ the olfactory system, including the olfactory bulb, a limbic paleocortex, is severely damaged. Only a few authors reported the occurrence of early olfactory deficits and degenerative changes in the olfactory system in AD. Averback ${ }^{1}$ has observed neurofibrillary tangles and senile plaques in the anterior olfactory nucleus and olfactory bulb in three AD cases. He reported the presence of granulovacuolar degeneration in cells of
From the University Institute of Pathology (SCZ, JM), Division of Neuropathology, 1011, CHUV, Lausanne, Switzerland, Department of Oto-Rhino-Laryngology, Head and Neck Surgery (OP), 1011, CHUV, Lausanne, Switzerland, Institute of Cellular Biology and Morphology (RK), University of Lausanne, 1005 Lausanne, Switzerland, Institute of Physiology (MK) University of Lausanne, 1005 Lausanne, Switzerland, University Department of Surgery (RM), Hollywood Private Hospital, Nedlands, Perth 6009, Western Australia, and Center for Neurovirolgy and Cancer Biology, Temple University, Philadelphia, USA (KK, JM). The work was carried out in the University Institute of Pathology, Division of Neuropathology, 1011, CHUV, Lausanne, Switzerland.

ReCEIVEd April 17, 2002. ACCEPTED In FINAL FORM SEPTEMBER 3, 2002. Reprint requests to: J. Miklossy, Temple University, Center for Neurovirolgy and Cancer Biology, College of Science and Technology, Biology of Life Science Building, 1900 North 12th Street, 015-96, Philadelphia, PA 10122 
the anterior olfactory nucleus. In 10 age-matched control cases neither plaques nor tangles were found. Hyman ${ }^{2}$ reported similar findings in $10 \mathrm{AD}$ patients. Esiri and Wilcock ${ }^{3}$ demonstrated neuronal loss and neurofibrillary tangles in the anterior olfactory nucleus in six AD patients whereas the 10 control cases were without any tangles or neuropil threads. In four AD cases Ohm and Braak $^{4}$ observed neurofibrillary tangles and curly fibers in the anterior olfactory nucleus and in all layers of the olfactory bulb except the outer fibrous layer. The four age-matched controls were without plaques and tangles. Mann ${ }^{5}$ reported occurrence of senile plaques and neurofibrillary tangles in the olfactory system, not only in AD patients and cases with Down's syndrome, but also in a few age-matched control cases without dementia. Ulrich ${ }^{6}$ has also observed plaques and tangles in 12 of 51 non-demented patients aged 55 to 64 years. Recently, Kovacs

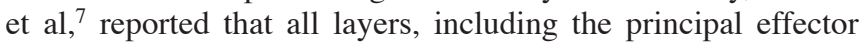
cells and mitral cells of the olfactory bulb, are severely affected in $\mathrm{AD}$ as well as in normal aging.

The number of cases studied with respect to the involvement of the olfactory bulb and tract is limited and the association between the frequency and severity of the degenerative changes in the olfactory bulb and tract with those of the cerebral cortex in AD remains to be established. Therefore, the goal of the present study was to analyze the olfactory system (olfactory bulb and tract) in a representative number of autopsy cases. Based on a semiquantitative histological analysis, the frequency and severity of these olfactory changes were compared with those of the cerebral cortex. The results obtained showed a statistically significant correlation between the cortical and olfactory degenerative changes in AD.

\section{MATERIAL AND METHODS}

One hundred and ten autopsy cases were used for this study. Brains of 109 consecutive autopsy cases with ages ranging between 44 and 93 years and the brain of a young patient (44years-old) with the clinical diagnosis of familial early onset AD (FAD) were investigated. In this FAD case, a genetic analysis for the detection of Presenilin-1 (PS-1) mutation was performed. The coding region of the PS-1 gene was analyzed by using intronic primers to amplify each coding exon of PS-1 through polymerase chain reaction and direct sequencing as previously described. ${ }^{8}$ The genetic analysis was also performed in two unaffected siblings and 50 control subjects.

From the formalin fixed brains, $3 \times 2 \times 0.5 \mathrm{~cm}$ large tissue samples were taken from the following cortical areas: temporal (including entorhinal cortex and hippocampus), frontal (Brodmann's area 8 and 9) and parietal (Brodmann's area 39) associative cortices. The olfactory bulb and tract were also analyzed in all cases. All these tissue samples were embedded in paraffin and for the visualization of the AD-type degenerative changes $5 \mu \mathrm{m}$ thick paraffin sections were stained with the Gallyas silver technique, Thioflavin S, Congo red, and were immunostained with a monoclonal antibody, which recognizes amino acid residues 8-17 of the amyloid- $\beta$ protein (DAKO Diagnostics AG, Switzerland, M 872, dil. 1:100).9,10 For immunostaining the avidin-biotin-peroxidase technique was used. Before immunostaining, the sections were pretreated with formic acid.
A semiquantitative analysis of the density of senile plaques, neurofibrillary tangles and neuropil threads (NT) was performed in all cortical areas mentioned above as well as in the olfactory bulb and tract using the same histological criteria as described in detail in two previous reports. ${ }^{9,10}$ The analysis of senile plaques was made on Thioflavin-S and on $\beta$-amyloid immunostained sections and those of neurofibrillary tangles and neuropil threads on Thioflavin-S and Gallyas-stained sections. The use of two different techniques decreased errors due to staining artifacts. The densities of senile plaques, neurofibrillary tangles and neuropil threads were graded as negative (-); low (+): moderate (++) and high "+++". Two investigators checked all these sections independently. Their results were compared and in cases of a discrepancy in gradation, the sections were reviewed by both of them for a final conclusion.

The neuropathological assessment of the severity of cortical involvement was carried out in the following way: once the different cortical areas were semiquantitatively rated, they were correlated and finally staged according to Braak. ${ }^{11}$ On the basis of these analyses the cases were divided into four groups: cases with discrete $(\mathrm{AD}+$, Braak stages I-II), moderate (AD++, Braak stages III-IV) and with severe (AD+++, Braak stages V-VI) changes. Cases without any cortical degenerative changes were classified as negative (AD-). In addition, in all cases histological criteria for the neuropathological diagnosis of definite AD according to Khachaturian, ${ }^{12}$ CERAD ${ }^{13,14}$ and NIA-Reagan Institute ${ }^{15}$ were also tested.

For the statistical analysis, contingency tables $(4 \mathrm{x} 4)$ were computed using FREQ procedure from SAS Institute Inc. (SAS/STAT User's Guide, 1990, Version 6, Fourth Edition, Vol. $1)$. The significance of the association between olfactory and cortical degenerative changes was checked using $\chi^{2}$ and Fisher's test. In order to calculate the correlation coefficients the values of the semiquantitative analysis (grades "-", “+”, “++" and “+++") were transformed into numerical values $(0,1,2$ and 3 , respectively). The computed, nonparametric Spearman correlation coefficients were tested for significance.

\section{RESUlts}

Based on the neuropathological assessment of the severity of cortical AD-type changes the 110 cases studied were divided into four groups. There were 58 cases with discrete AD-type cortical changes (AD+; aged 44-93 years, mean 75.2y). In 53 of these the severity of the cortical involvement corresponded to Braak stages I-II. In the remaining five cases, only neuropil threads were found in the cerebral cortex without any tangles. The second group included 14 cases with moderate (AD++, Braak stages III and IV, aged 53-90 years, mean 85.2y) and the third group 19 cases with severe cortical involvement (AD+++, Braak stages V and VI, aged 44-93 years, mean 81.9y). The 19 cases with severe AD-type cortical changes (AD+++) were all demented and fulfilled the histological criteria of the definite diagnosis of $\mathrm{AD}$ following Khachaturian, ${ }^{12} \mathrm{CERAD}^{13,14}$ as well as the NIA-Reagan Institute. ${ }^{15}$ One of the 19 definite AD cases corresponded to the young FAD case where the genetic analysis revealed the presence of M233T mutation of the PS-1 gene. The mutation, present in other affected members of the family was not observed in the two unaffected siblings and 50 control 


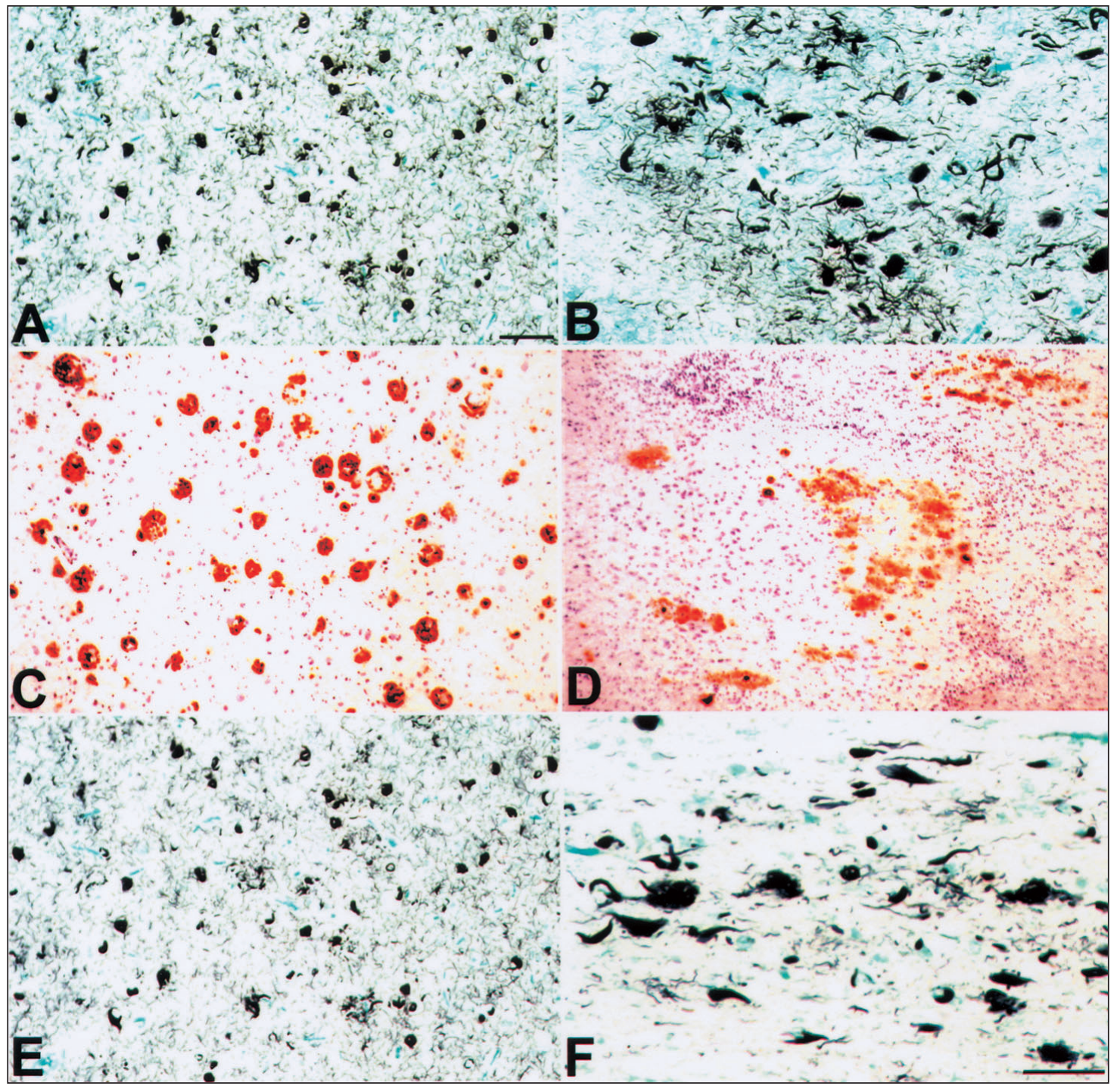

Figure 1: Alzheimer's type degenerative changes in the olfactory system in Alzheimer's disease (AD).

A-D: Photomicrographs illustrating the AD-type degenerative changes in the frontal associative cortex and in the olfactory bulb in a definite, sporadic $A D$ case. The accumulation of neurofibrillary tangles in the frontal cortex $(A)$ and in the olfactory bulb $(B)$ as visualized with the Gallyas silver technique. $C$ and $D$ show amyloid $\beta$ deposition in senile plaques of the frontal associative cortex (Brodmann's areas 8-9) and olfactory bulb, respectively. Avidin-biotin-peroxidase technique. $E$ and $F$ illustrate degenerative changes of the olfactory system in the case of a young familial Alzheimer's disease case with Presenilin-1 mutation (M233T). There is an important accumulation of neurofibrillary tangles in the frontal associative cortex $(E)$ and anterior olfactory nucleus $(F)$. Gallyas technique.

Scale bar in $A$ : $A$ and $E=200 \mu \mathrm{m} ; B=100 \mu \mathrm{m} ; C$ and $D=300 \mu \mathrm{m}$. Scale bar in $F=100 \mu \mathrm{m}$.

subjects. The fourth group consisted of 19 cases without any plaques, tangles or neuropil threads in the cerebral cortex (AD-; aged 44-73, mean 67y). These cases were considered as controls.

We have observed accumulation of neuropil threads, neurofibrillary tangles, but also of senile plaques in the olfactory system in all definite AD cases as illustrated in Figure 1, A-D. Severe AD-type degenerative changes were also present in the olfactory system in the young FAD case with PS-1 mutation (M233T) (Figure $1 \mathrm{E}$ and F).
As illustrated in Figure 2, the frequency of cases with neuropil threads (ONT) and neurofibrillary tangles (ONFT) in the olfactory system in the group with discrete cortical AD-type changes (AD+) corresponded to $75 \%$ and $30 \%$, respectively. These values increased to $100 \%$ (ONT) and $75 \%$ (ONFT), in the group with moderate $(\mathrm{AD}++)$ cortical lesions. All 19 cases with definite $\mathrm{AD}(\mathrm{AD}+++)$ showed tangles and neuropil threads $($ ONFT and ONT $=100 \%)$. Senile plaques $(\mathrm{OSP})$ were observed in only $2 \%$ of cases in the group with discrete (AD+), in $7 \%$ of 


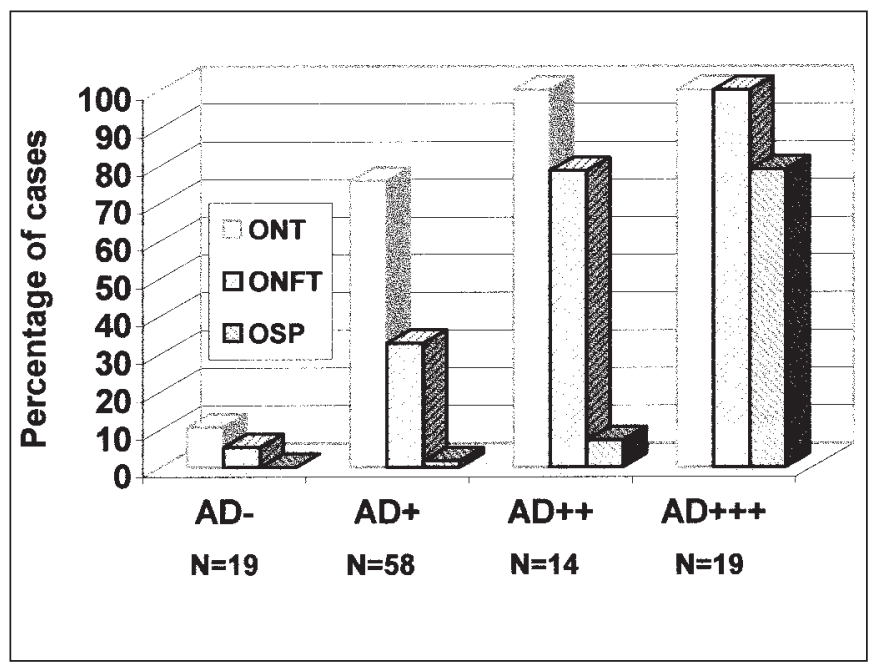

Figure 2: Frequency of the AD-type degenerative changes in the olfactory system in $A D$.

The graph illustrates the percentage of cases with neuropil threads (ONT), neurofibrillary tangles (ONFT) and senile plaques (OSP) in the olfactory system, without distinguishing the severity grades of the degenerative changes, in the four groups of cases, i.e., without ( $A D-)$, with discrete $(A D+)$, moderate $(A D++)$ and with severe $(A D+++)$ cortical changes. The percentage of cases with ONT, ONFT and OSP progressively increased with the increasing severity of the cortical changes. The percentage of cases with ONFT and ONT in the olfactory system is high in the three groups with cortical AD-type changes $(100 \%$ in the group of definite $A D+++$ cases) and very low in the control group. The accumulation of OSP occurs, mainly, in advanced stages of cortical degeneration $(A D+++)$. The association between the frequency of the degenerative changes in the olfactory system and cerebral cortex was statistically significant (Fisher test $P<0.001$ ).

cases with moderate (AD++) and in $79 \%$ of cases with severe cortical changes ( $\mathrm{AD}+++)$, whereas no plaques were found in the 19 controls. Interestingly, neurofibrillary tangles and/or neuropil threads were also observed in the olfactory system in two control cases $(\mathrm{ONT}=10.5 \%$; ONFT $=5.3 \%)$.

The percentage of cases with OSP in the groups with discrete $(\mathrm{AD}+)$ and moderate $(\mathrm{AD}++)$ cortical changes was very low when compared to the percentage of cases with ONFT or ONT in the same groups. When the frequency of cases with ONFT was compared with that of the cases with NT the percentage of cases with neuropil threads was higher, except in the definite AD group $(\mathrm{AD}+++)$ where $100 \%$ of cases showed both neuropil threads and neurofibrillary tangles.

The semiquantitative analysis of plaques, tangles and neuropil threads in both the olfactory system and cerebral cortex enabled us to compare the density of olfactory and cortical degenerative changes. Figure 3 shows that the mean density of neuropil threads, neurofibrillary tangles and senile plaques in the olfactory system increased with the increasing severity of the cortical changes. The correlation was significant $(\mathrm{P}<0.001)$ between the severity of the AD-type cortical changes and the density of ONT, ONFT and OSP (Spearman correlation coefficients $\mathrm{R}$ were $0.79,0.70$ and 0.61 , respectively). The percentage of cases with severe accumulation of neuropil threads

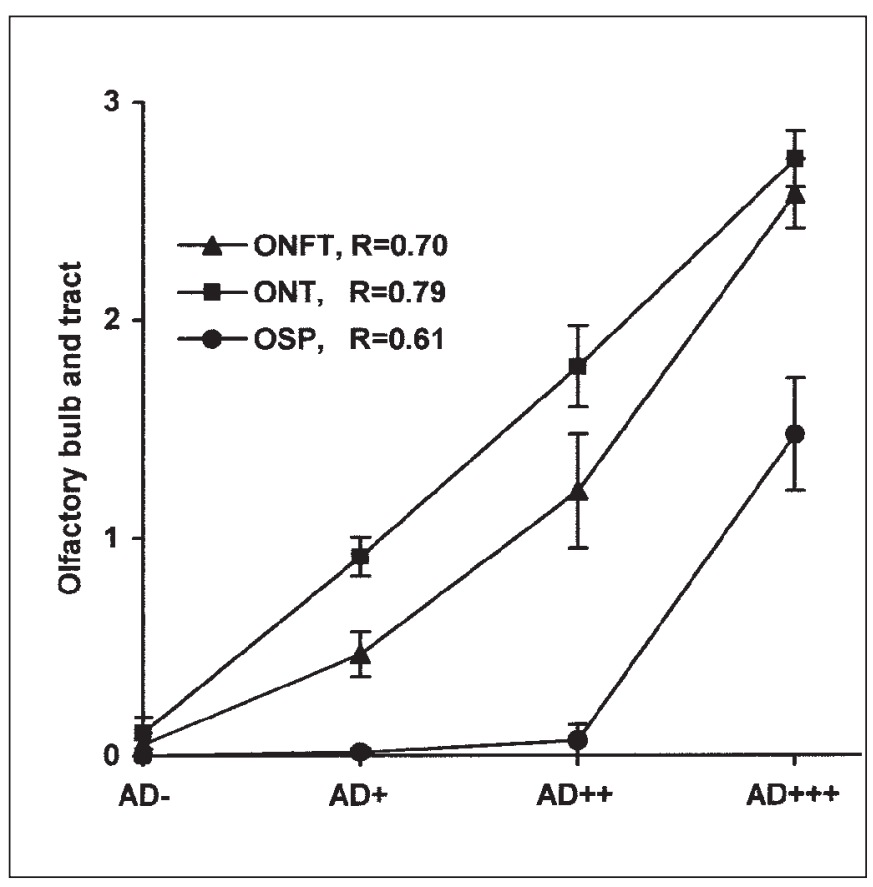

Figure 3: Severity of the AD-type degenerative changes in the olfactory system in $A D$.

The severity of the olfactory degenerative changes was significantly $(P<0.001)$ associated with the severity of the cortical involvement. The densities of neurofibrillary tangles (ONFT), neuropil threads (ONT) and senile plaques (OSP) in the olfactory system in the four groups of cases without $(A D-)$, with discrete $(A D+)$, moderate $(A D++)$ and with severe $(A D+++)$ cortical involvement, progressively increased with the severity of the cortical involvement.

The densities of tangles, neuropil threads and senile plaques were graded in the following way: absence of lesion $=0$; low $=1 ;$ moderate $=2$; high $=3$. The symbols in the graph represent mean values \pm SEM of the density of $A D$-type degenerative changes in the olfactory system in the four different groups. R: Spearman correlation coefficient $(N=110)$.

or neurofibrillary tangles in the olfactory system was higher in the definite $\mathrm{AD}$ group $(\mathrm{ONT}+++=79 \%$; ONFT $+++=68 \%)$, than in the groups with moderate ( $14 \%$ for both) or discrete $(3 \%$ for both) cortical changes (not shown). Severe accumulation of senile plaques occurred only in the group with definite $\mathrm{AD}$ $(\mathrm{OSP}+++=26 \%)$.

The neurodegenerative changes in the olfactory bulb and tract were also correlated with those of the entorhinal cortex (ENT, ENFT, ESP). Figure 4 shows that the mean density of neuropil threads, neurofibrillary tangles and senile plaques in the olfactory system increased with the increasing severity of the degenerative changes in the entorhinal cortex. The correlation was significant $(\mathrm{P}<0.001)$ between ONT and ENT, ONFT and ENFT but also between OSP and ESP (Spearman correlation coefficients $\mathrm{R}$ were $0.79,0.69$ and 0.54 , respectively).

The statistical analysis using Fisher's test showed a significant association $(\mathrm{P}<0.001)$ between the cortical and olfactory changes, not only with respect to their frequency but also with respect to their severity. 


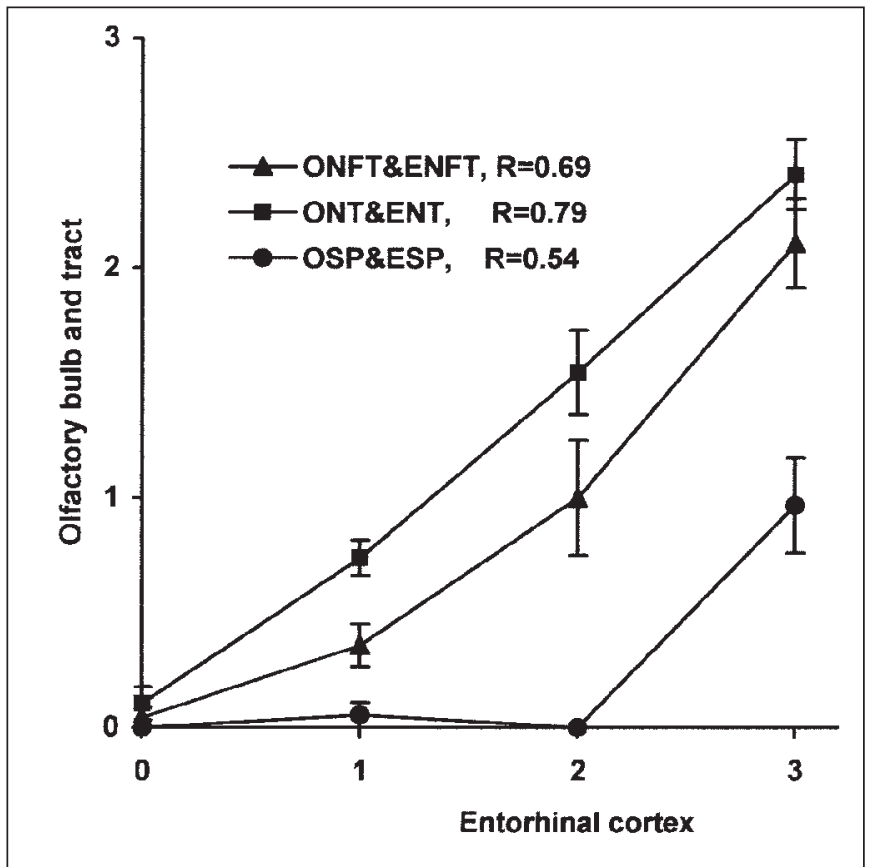

Figure 4: Correlation of the severity of the AD-type degenerative changes in the olfactory system and entorhinal cortex.

The severity of the degenerative changes in the olfactory bulb and tract as well as entorhinal cortex was significantly $(P<0.001)$ associated. The density of neurofibrillary tangles (ONFT), neuropil threads (ONT) and senile plaques $(O S P)$ in the olfactory system progressively increased with the increasing density of tangles (ENFT), neuropil threads (ENT), and senile plaques (ESP) in the entorhinal cortex. The densities of neurofibrillary tangles, neuropil threads and senile plaques were graded in the following way: absence $=0$; low $=1$; moderate $=2$; high $=3$. The symbols in the graph represent mean values \pm SEM of the density of ONFT, ONT and OSP with respect to the involvement of the entorhinal cortex. $R$ : Spearman correlation coefficient $(N=110)$.

\section{Discussion}

Olfactory nerve cells in the olfactory epithelium project to the olfactory bulb. Primary olfactory fibers synapse with the descending dendrites of large mitral cells in the olfactory glomeruli. Axons of mitral and tufted cells enter the olfactory tract and provide input to the anterior olfactory nucleus as well as to the central projections of the olfactory system. The anterior olfactory nucleus gives rise to a recurrent collateral to the bulb and to a crossed projection through the anterior commissure. The olfactory tract projects to the prepyriform cortex, corticomedial nuclei of amygdala, and parahippocampal gyrus including entorhinal cortex, all severely damaged in early stages of AD. ${ }^{16,17}$ Such observations have led to the "olfactory hypothesis" suggesting that the olfactory pathway may be the site of initial involvement in $\mathrm{AD} .^{5,18-20} \mathrm{Mann}^{5}$ has proposed that the olfactory tracts may provide a portal of entry to the brain for any putative pathogenic agent(s) that may be responsible for the induction of senile plaques and/or neurofibrillary tangles. With subsequent spread, perhaps by cortico-cortical connecting fibers, the degenerative process may involve the rest of the hippocampal formation and association areas of neocortex in the parietotemporal and frontal lobes. ${ }^{5}$

Several clinical studies have demonstrated deficits in olfactory recognition in patients with $\mathrm{AD} .^{21}$ Davies $^{22}$ reported severe loss of myelinated axons $(52 \%)$ in the olfactory tract. Some authors have reported that AD-type degenerative changes occur in the olfactory bulb and tract in AD, Down's syndrome as well as in aged people. ${ }^{1-7,23}$

Our results show that $\mathrm{AD}$-type degenerative changes in the olfactory bulb, tract and anterior olfactory nucleus occur in a high percentage of cases with AD-type cortical changes. The number of cases with olfactory involvement is high, not only in the group of cases with severe, but also in the groups of cases with discrete and moderate degenerative cortical changes. The severity of the olfactory involvement progressively increases with the increasing severity of the cortical changes. All cases with definite $\mathrm{AD}$ showed important accumulation of AD-type degenerative changes, in the olfactory bulb and tract, including the young FAD cases with PS-1 (M233T) mutation, whereas in the control group the percentage of cases with olfactory changes was very low. It is of interest to notice that recently, Utsumi et $\mathrm{al}^{24}$ have found that PS-1 mRNA is strongly expressed early in the olfactory bulb of the embryonic rat (day 20), before the expression of amyloid- $\beta$ protein precursor (A $\beta P P)$ mRNA and suggested that the PS- 1 and A $\beta$ PP cooperatively play pivotal roles in the development of the olfactory system.

The fact that neuropil threads and neurofibrillary tangles accumulate in the olfactory bulb and tract not only in cases with severe, but also with discrete and moderate cortical changes, indicate that the olfactory system is involved early in the degenerative process of AD. Unlike neurofibrillary tangles and neuropil threads, senile plaques occur mostly in cases with severe cortical involvement. These results are in agreement with the observations of Mann, ${ }^{5}$ who regularly found neurofibrillary tangles in the olfactory bulb and tract in patients with AD, Down's syndrome and in non-demented individuals but has observed senile plaques only in a few cases. These observations indicate that neuropil threads and neurofibrillary tangles appear in the olfactory bulb and tract in early stages of the degenerative process, preceding the accumulation of senile plaques.

The statistical analysis showed a significant association (Fisher's test $\mathrm{P}<0.001$ ) between the involvement of the olfactory bulb and tract and cerebral cortex, with respect to the frequency and density of the degenerative changes. A strong correlation was found between the involvement of entorhinal cortex and olfactory system. Neurofibrillary tangles and neuropil threads appear in the olfactory bulb and tract as early as in the entorhinal cortex.

In two controls, without cortical degenerative changes, tangles and/or curly fibers were already present in the olfactory bulb and tract. These results indicate that the peripheral part of the olfactory system is involved in early stages of $\mathrm{AD}$ and are in agreement with the clinical observations of Doty ${ }^{25}$ and Murphy ${ }^{26}$ who have reported olfactory deficits in subjects with only mild symptoms of AD. The degenerative changes of the olfactory bulb and tract, entorhinal cortex, together with the fibrillary changes of the ependymal layer and choroid plexus epithelial cells, as shown in our previous study, ${ }^{9}$ appear to be the earliest manifestations of the degenerative process in the central nervous system in AD. 
In conclusion, our results indicate a highly significant correlation between the olfactory bulb and tract and cerebral cortex regarding the frequency and severity of the degenerative AD-type changes. The appearance of degenerative changes in this peripheral part of the olfactory system occurs early in the course of $\mathrm{AD}$, in the preclinical stages of the disease.

\section{ACKNOWLEDGEMENTS}

We thank E. Bernardi, P. Darekar, S. Gros and S. Trepey for their technical assistance. The work was supported by grants of the Societe Academique Vaudoise and by the University Institute of Histology, Fribourg, Switzerland.

\section{REFERENCES}

1. Averback P. Two new lesions in Alzheimer's disease. Lancet 1983; 2: 1203.

2. Hyman BT, Arriagada PV, Van Hoesen GW. Pathologic changes in the olfactory system in aging and Alzheimer's disease. Ann N Y Acad Sci 1991; 640: 14-19.

3. Esiri MM, Wilcock GK. The olfactory bulbs in Alzheimer's disease. J Neurol Neurosurg Psychiatry 1984; 47: 56-60.

4. Ohm TG, Braak E. Olfactory bulb changes in Alzheimer's disease. Acta Neuropathol 1987; 73: 365-369.

5. Mann DM, Tucker CM, Yates PO. Alzheimer's disease: an olfactory connection? Mech Aging Develop 1988; 42: 1-15.

6. Ulrich J. Alzheimer changes in nondemented patients younger than 65: possible early stages of Alzheimer's disease and senile dementia of Alzheimer type. Ann Neurol 1985; 17: 273-277.

7. Kovacs T, Cairns NJ, Lantos PL. $\beta$-Amyloid deposition and neurofibrillary tangle formation in the olfactory bulb in ageing and Alzheimer's disease. Neuropathol Appl Neurobiol 1999; 25: 481-491.

8. Kwok JB, Taddei K, Hallupp M, et al. Two novel (M233T and R278T) presenilin-1 mutations in early-onset Alzheimer's disease pedigrees and preliminary evidence for association of presenilin-1 mutations with a novel phenotype. Neuroreport 1997; 8: 1537-1542.

9. Miklossy J, Kraftsik R, Pillevuit O, et al. Curly fiber and tangle-like inclusions in the ependyma and choroid plexus- a pathogenetic relationship with the cortical Alzheimer-type changes? J Neuropathol Exp Neurol 1998; 57: 1202-1212.

10. Fonte J, Miklossy J, Atwood C, Martins R. The severity of cortical Alzheimer's type changes is positively correlated with increased amyloid- $\beta$ levels: resolubilization of amyloid- $\beta$ with transition metal ion chelators. J Alzheimer Dis 2001; 3: 209-219.

11. Braak H, Braak E, Bohl J. Staging of Alzheimer-related cortical destruction. Eur Neurol 1993; 33: 403-408.

12. Khachaturian ZS. Diagnosis of Alzheimer's disease. Arch Neurol 1985; 42: 1097-1105.

13. Morris JC, Mohs RC, Rogers H, Fillenbaum G, Heyman A. Consortium to establish a registry for Alzheimer's disease (CERAD) clinical and neuropathological assessment of Alzheimer's disease. Psychopharm Bull 1988; 24: 641-644.

14. Mirra SS, Hart MN, Terry RD. Making the diagnosis of Alzheimer's disease. Arch Pathol Lab Med 1993; 117: 132-144.

15. Newell KL, Hyman BT, Growdon JH, Hedley-Whyte ET. Application of the National Institute on Aging (NIA)-Reagan Institute criteria for the neuropathological diagnosis of Alzheimer's disease. J Neuropathol Exp Neurol 1999; 58: 11471155.

16. Powell TPS, Cowan WM, Reisman G. Olfactory relationships of the diencephalon. Nature 1963; 199: 710-712.

17. Pearson RCA, Esiri MM, Hiorns RW, Wilcock GK, Powell TPS. Anatomical correlates of the distribution of the pathological changes in the neocortex in Alzheimer's disease. Proc Natl Acad Sci 1985; 82: 4531-4534.

18. Rogers J, Morrison JH. Quantitative morphology and regional and laminar distributions of senile plaques in Alzheimer's disease. J Neurosci 1985; 5: 2801-2808.

19. Roberts E. Alzheimer's disease may begin in the nose and may be caused by aluminosilicates. Neurobiol Aging 1986; 7: 561-567.

20. Perl DP, Good PF. Uptake of aluminum into central nervous system along nasal-olfactory pathways. Lancet 1987; 1: 1028.

21. Doty RL. Olfactory capacities in aging and Alzheimer's disease. Psychophysical and anatomic considerations. Ann N Y Acad Sci 1991; 40: 20-27.

22. Davies DC, Brooks JW, Lewis DA. Axonal loss from the olfactory tracts in Alzheimer's disease. Neurobiol Aging 1993; 14: 353357.

23. Talamo BR, Rudel R, Kosik KS, et al. Pathological changes in Alzheimer's disease. Nature 1989; 337: 736-739.

24. Utsumi M, Sato K, Tanimukai H, et al. Presenilin-1 mRNA and $\beta$ amyloid precursor protein mRNA are expressed in the developing rat olfactory and vestibulocochlear systems. Acta Otolaryngol 1998; 118: 549-553.

25. Doty RL, Reyes PF, Gregor T. Presence of both odour identification and detection deficits in Alzheimer's disease. Brain Res Bull 1987; 18: 597-600.

26. Murphy C, Gilmore MM, Seery CS, Salmon DP, Laskar BR. Olfactory thresholds are associated with degree of dementia in Alzheimer's disease. Neurobiol Aging 1990; 11: 465-469. 